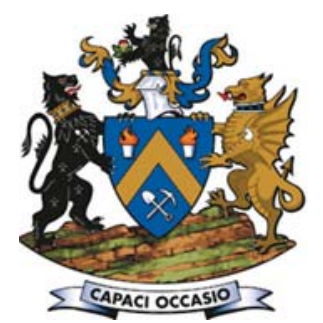

\title{
Operational changes enable Namdeb's Southern Coastal Mining team to reduce risk and increase productivity as we advance deeper into the Atlantic Ocean
}

\author{
by S. Kirkpatrick* and J. Mukendwa ${ }^{\dagger}$
}

\section{Synopsis}

The mining operation at Namdeb's Southern Coastal Mine (SCM) is unique. It targets gravel layers up to $30 \mathrm{~m}$ below sea level, which continue to dip deeper, further west, under the Atlantic Ocean. On this storm-dominated coastline, severe water seepage into mining areas, rugged orebody footwall characteristics, and highly variable resource grades all contribute to a challenging operational environment. Namdeb has a proud history of innovation, and as the mine progresses further westwards and associated technical and economic challenges increase, this innovative culture has become essential to the future of the mine. The Theory of Constraints (ToC) has been widely used at SCM, and across the mining discipline, to focus efforts on improving overall business profitability. Through analysis of the mining processes, opportunities were identified, solutions developed, and initiatives implemented with staggering results across all three mining disciplines, i.e. stripping, load and haul, and bedrock bulking and cleaning. This paper outlines the solutions adopted and the results of the ToC analysis.

\section{Keywords}

mining, Namibia, theory of constraints, improvement, beach nourishment.

\section{Introduction}

Southern Coastal Mine (SCM) is one of three Namdeb operations located in the southwestern corner of Namibia, between the Orange River in the south, the Namib Desert to the east and the Atlantic Ocean to the west (Figure 1). These three geographical features set the backdrop for the world's greatest marine diamond mining placer (Badenhorst, 2003). SCM is situated along the coastline extending from the mouth of the Orange River to Chameis Bay approximately $120 \mathrm{~km}$ to the north. The active mining area, called Mining Area 1 (MA1) is, however, limited to very narrow strip, $30 \mathrm{~km}$ in length, in the south of the licence area, close to the town of Oranjemund.

Namdeb, a wholly owned subsidiary of Namdeb Holdings, is a 50/50 joint venture between De Beers and the Government of Namibia. Diamonds were first discovered along the Namibian coastline in April 1908, close to the town of Luderitz, but mining operations started in the SCM mining area only in February 1929 (Schneider, 2009). Initially all
Namdeb mining operations exploited massive land-based deposits, producing nearly 40 million carats from MA1 between 1920 and 1977 (Schneider, 2009) when mining targeted onshore raised beaches west of the high water line. Since 1977 however, SCM and Namdeb have developed a unique mining method to economically extract the resource which extends westward under the Atlantic Ocean.

Both the location and mining method unsurprisingly present a unique set of challenges, making economic extraction increasingly difficult as the orebody dips deeper and deeper to the west beneath the sea. Innovation and operational improvement remain crucial to extending the life-of-mine (LoM) of SCM. A number of fundamental changes have been implemented at SCM over the last 3 years which have reduced the operational risk and increased productivity of the core mining functions. This paper describes these changes and their direct results.

\section{Geology}

The Orange River system (Figure 2) has transported coarse gravel material, including diamonds, from the southern African subcontinent to the west coast of South Africa and Namibia since Cretaceous times (Jacob, 2005; Bluck, Ward, and de Witt, 2005). At least two phases of uplift of the interior resulted in renewed river energy, increased erosive power, and associated coarse river load, manifesting as deeply bedrock-incised fluvial channels with remnant abandoned terraces and associated gravel deposits along

* Mining Optimisation, Southern Coastal Mine, Namibia.

+ Southern Coastal Mine, Namibia.

(c) The Southern African Institute of Mining and Metallurgy, 2019. ISSN 2225-6253. This paper was first presented at the Diamonds - Source to Use 2018 Conference, 11-13 June 2018, Birchwood Hotel and OR Tambo Conference Centre, JetPark, Johannesburg, South Africa. 


\section{Operational changes enable Namdeb's Southern Coastal Mining team to reduce risk}

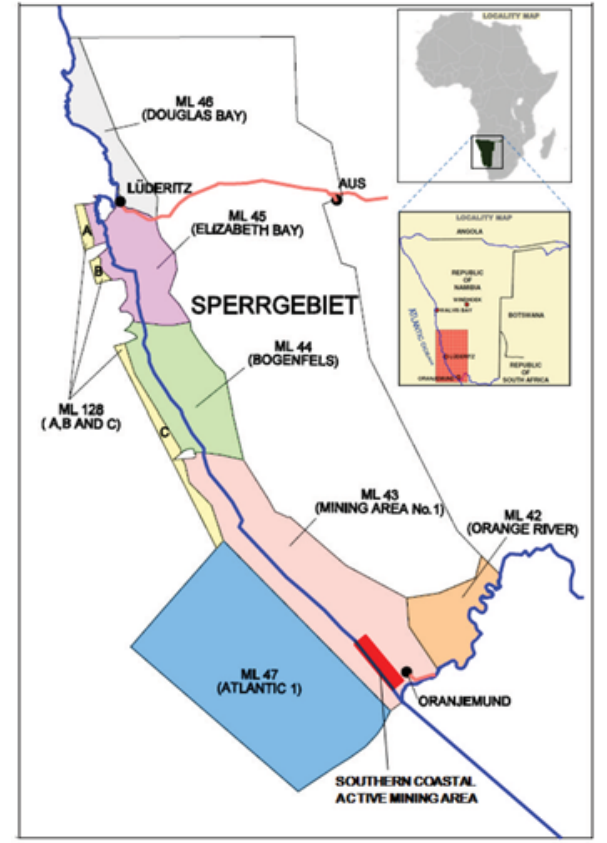

Figure 1-Location map for Namdeb's mining licence areas, indicating the active Southern Coastal Mining area in the south

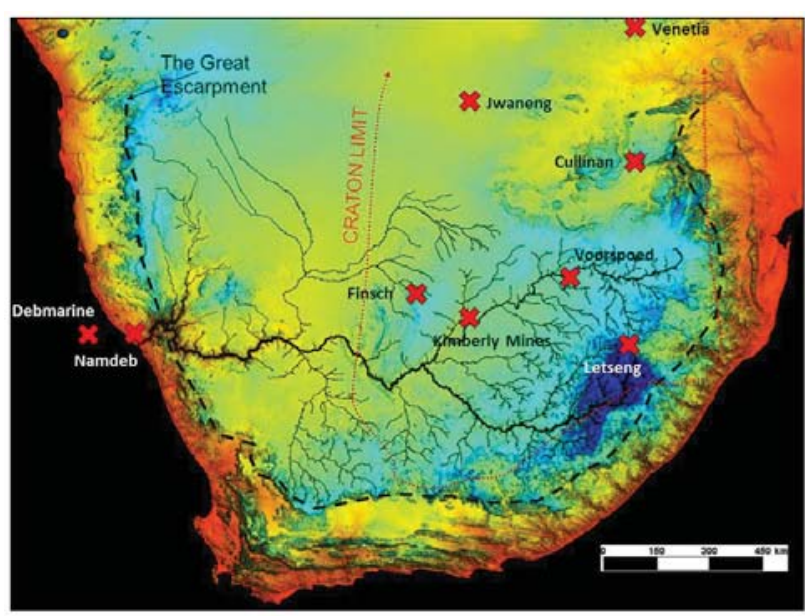

Figure 2-Orange River system and location of major current Southern African diamond mines (Orapa complex not shown)

the river course. The river ultimately deposited its load of diamondiferous material into the Atlantic Ocean, where marine reworking processes subsequently further upgraded the diamondiferous gravel during repeated sea-level transgressions and regressions (Bluck, Ward, and de Witt, 2005), resulting in a placer deposit comprising 95\% gem quality stones.

The wave-dominated west coast of Namibia is one of the most vigorous coastlines in the world; $90 \%$ of the waves have a height of $0.75-3.25 \mathrm{~m}$, with an average of $1.75 \mathrm{~m}$ for winter and $1.5 \mathrm{~m}$ for summer (Rossouw, 1981; de Decker, 1988). The coastline is also exposed to storm events associated with passing frontal systems (Smith, 2003) and wave heights above $9 \mathrm{~m}$. This, in combination with the longperiod swell and a strong prevailing SW wind regime (Rogers, 1977) produces a strong northerly longshore drift, capable of moving cobble-sized gravel at depths of $15 \mathrm{~m}$ (de Decker, 1988). Consequently, the sand component of the outfall of the Orange River is transported offshore and north by the longshore drift system, and at certain points it is washed back onshore to feed the Namib Sand Sea. The gravel (and diamond) component of the outfall is retained along the coast for about $300 \mathrm{~km}$ where it has been reworked into a series of coarse beaches underlain by the gullied and potholed Late Proterozoic metasedimentary basement. This rugged basement forms fixed trapsites which further upgrade the diamondiferous gravel on wave-cut platforms (Jacob et al., 2006).

Four types of gravel beaches have been identified in the Pleistocene-Holocene gravels of the Namibian coastal strip north of the Orange River (Spaggiari et al., 2006; Schneider, 2008). Near the river mouth, gravel accumulates as spits with associated back-barrier lagoons; northwards, with increasing distance from the point source of sediment supply, spits give way to barrier beaches, linear beaches, and finally pocket beaches where the coastline forms natural bays. The active SCM mining areas are situated within the zone of barrier beaches and linear beaches.

The diamondiferous orebody comprises a coarse gravel facies that directly overlies and infills a rugged, gullied, and potholed predominantly schistose bedrock footwall. Clay footwall areas form a lesser proportion of the mine plan and are generally less rugged. The ore horizon is overlain by a sandy overburden comprising both marine and accreted sand with minor gravel terrace components.

\section{Mining method}

The mining operation at SCM has transitioned from an extensive above sea-level, volume-driven mining operation, through westward expansion of the mining faces, to an operation largely below sea level. To enable movement of the mining areas westwards a process of deliberate coastal accretion is used to transport and deposit sand onto the beaches at specific areas and at defined rates. Various accretion systems are employed; these include conveyors, treatment plant tailings disposal, and the dumping of overburden material, which is part of the overburden stripping process. The sand deposition profiles are fed into an accretion model, which has been developed and calibrated over a number of years. This model is used to predict the annual $+2 \mathrm{~m}$ contour positions used in the mine planning process. The $+2 \mathrm{~m}$ contour is the contour that runs along the beach at $2 \mathrm{~m}$ above mean sea level (AMSL) and defines which areas will be available for future mining. The mine plan and accretion model are interdependent; changes in the mine plan alters the deposition points and volumes, resulting in changes to the accretion line predictions. Figure 3 shows the five-year waste deposition volumes and associated annual accretion prediction lines.

The sub-sea-level mining operations at SCM, directly adjacent to the Atlantic Ocean, make operations vulnerable to frequent storm events. Workings are protected from storm events by seawalls constructed along the western side of the mining area. Prior to opening a new mining cut, seawalls are constructed along the western side of the cut to a height of between $7 \mathrm{~m}$ and $10 \mathrm{~m}$ above sea level, with a minimum width of $20 \mathrm{~m}$. To further mitigate risk during storm events, the seawalls are set back a minimum of $25 \mathrm{~m}$ east of the 


\section{Operational changes enable Namdeb's Southern Coastal Mining team to reduce risk}

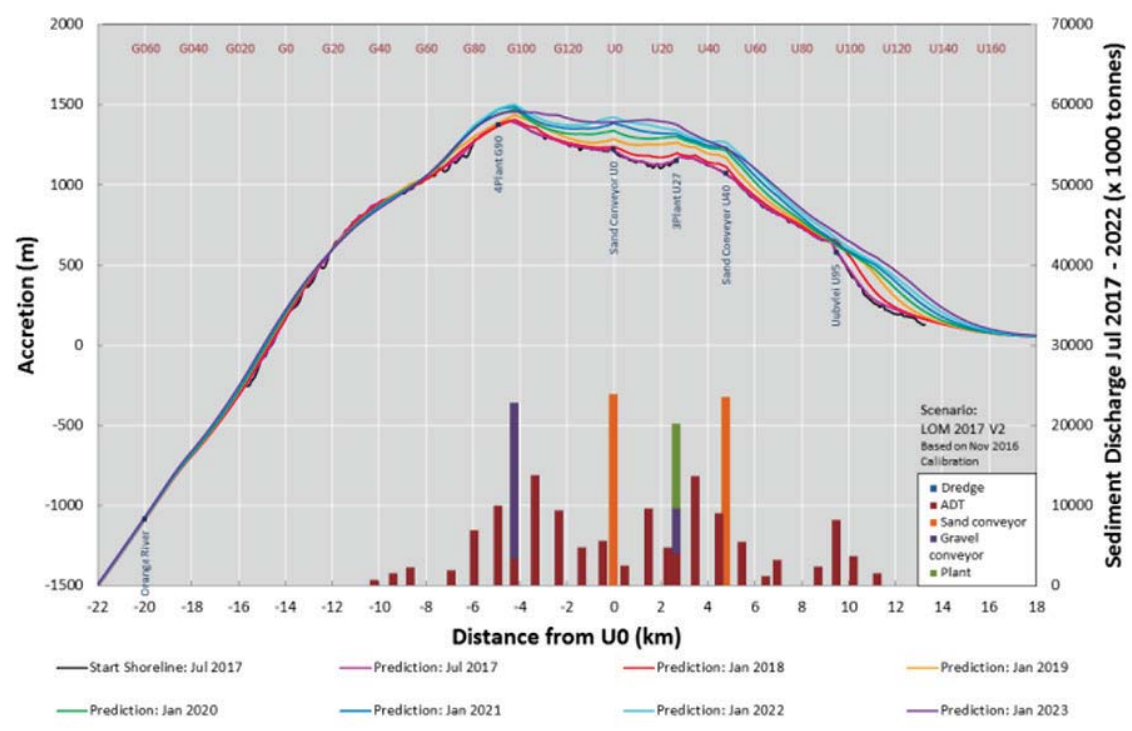

Figure 3-Accretion model showing the accretion tonnages from the different accretion processes and the associated annual advance of the $+2 \mathrm{~m}$ contour (note: east-west axis is $6 \times$ exaggerated)

$+2 \mathrm{~m}$ contour and are often widened to $30 \mathrm{~m}$. Figure 4 outlines a simplified version of the cycle of accretion, seawall construction, and mining.

On completion of the seawall, the stripping fleet, consisting of $80 \mathrm{t}$ excavators and $40 \mathrm{t}$ articulated dump trucks (ADTs), then focuses on loading overburden material out of the mining cut and dumping it on the beach to the west of the seawall (Figure 5). This material dumped is thus made available for beach accretion, creating space for future mining.

Material close to surface is generally dry but once the phreatic line has been intersected, seepage from the sea ingresses into the mining cut resulting in much wetter overburden material and, consequently, the need for water management. Water channels are constructed along the eastern toe of the seawall to channel water to a sump where pumps remove water from the cut. Channels and sumps are maintained and deepened as mining progresses down to bedrock. Once excavators 'hit bedrock', i.e. once the excavator bucket starts to scrape against the highest bedrock points, the stripping operation has reached completion and bedrock teams can move in to start bulking operations.

Bedrock teams consist of both a bulking and a cleaning crew (Figure 6) who, for security reasons, work only during day shift. The bulking process is used to clean out most of the material from bedrock gullies and potholes using hydraulic equipment to break open narrow areas, load out material, and finally scrape the bedrock clean with bullnose buckets. The bulking fleet includes a bulldozer, a $60 \mathrm{t}$ excavator, a number of smaller 20 thydraulic excavators, and $20 \mathrm{t}$ hydraulic hammers. When cemented material is encountered, hydraulic hammers are used to break this harder material out, after which dozers and the $60 \mathrm{t}$ excavator are used to transfer material to loading areas, where stockpiles can be loaded and hauled to the plant for treatment.

Bedrock cleaning crews complete the final vacuuming of the bedrock, removing all fine gravel particles lodged in cracks, potholes, and gullies. Cleaning crews use industrial
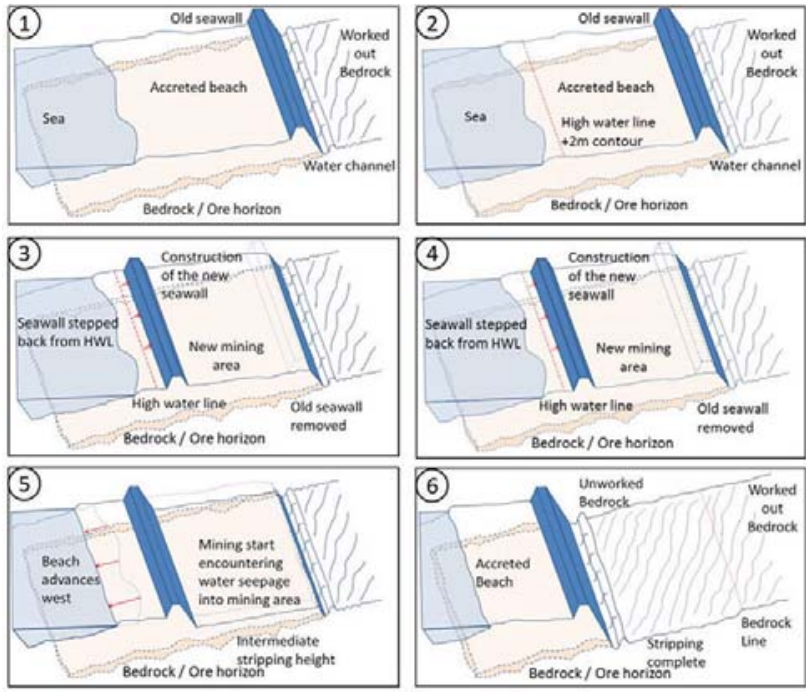

Figure 4-Graphical depiction of the stripping and accretion sequence at SCM
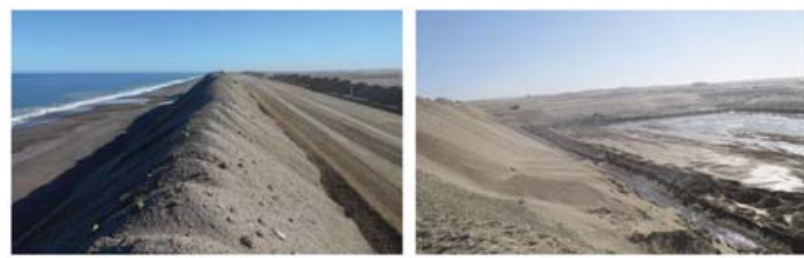

Figure 5-Photos taken on the seawall showing the sea to the west and the mining cut to the east
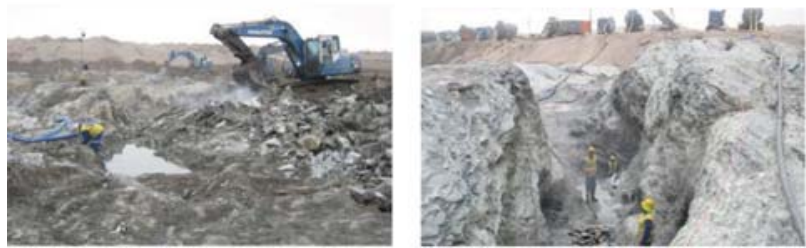

Figure 6-Photos of bedrock operations, showing bulking on the left and some very deep bedrock gullies on the right 


\section{Operational changes enable Namdeb’s Southern Coastal Mining team to reduce risk}

vacuum units which suck up material into a collection bin that is then trammed to the plant. As many as 12 vacuum units can be used on a single site with two operators manning each suction pipe. Profiles of the bedrock horizon are undulating with variable ruggedness; some areas having a relatively flat profile while others have gullies and potholes more than $5 \mathrm{~m}$ deep.

Load and haul $(\mathrm{L} \& \mathrm{H})$ teams are used to transport bulked material from the bedrock sites to the plant and ensure the plant feed rates are maintained. The L\&H fleet comprises 320 $\mathrm{kW}$ front-end loaders and $40 \mathrm{t}$ rigid frame trucks which tram all diamondiferous material from the mining sites to the plant.

Plant feed material from both $\mathrm{L} \& \mathrm{H}$ and bedrock collection bins are treated through a simple process comprising primary and secondary crusher circuits, a series of scrubbers, and finally a dense medium separation (DMS) plant. Plant concentrate is taken to the Red Area Complex (RAC) for final diamond recovery. Plant tailings are conveyed to the sea, thus contributing to beach accretion.

\section{Environmental}

Namdeb has a valid environmental clearance certificate, issued under the Environmental Management Act (2007) and Regulations (2012) of Namibia, for all relevant mining licence areas, including ML43 which covers Southern Coastal Mine.

To ensure continued compliance, Namdeb conducts a number of monitoring programmes, audits, and stakeholder engagement sessions that include:

> Annual coastal marine monitoring of its beaches

> Annual IS014001 environmental management system audit

- Third-party legal audit conducted every two years

> Annual Namdeb Environmental Stakeholders Forum

> Quarterly meetings of the De Beers Marine Risk platform

> Namdeb Marine Scientific Advisory Committee.

\section{Improvements}

\section{Overview}

As the SCM operation has advanced westwards beneath sea level, the operation has been exposed to ever-increasing risk; greater possibility of a seawall breach, increased overburden stripping volumes and costs due to deeper mining cuts, increasing water seepage into the workings, which increases pumping volumes and costs, as well as lower confidence in the resource estimation due to practical sampling constraints. These factors all impact on an already marginal operation.

Before progressing with improvement initiatives, a solid mine plan and effective execution were deemed to be paramount to the success of any improvement projects. Following the stabilization of the operation, the Theory of Constraints (ToC) has been widely used at SCM, and especially across the mining discipline, to focus efforts on improving overall business profitability. The ToC is a management philosophy introduced by Eliyahu M. Goldratt in 1984, that states that a system output is limited by one or more constraints and that an optimum system runs the constraint or bottleneck at maximum capacity (Goldratt,
1992). This also requires that all other processes are focused on ensuring the throughput at the constraint is maximized.

Defining the mining processes and identifying bottlenecks focused the team on where opportunities exist for value-adding improvement. Following the initial ToC analysis, availability of material to feed the plant was highlighted as the key bottleneck within SCM. On further analysis, across the other mining processes, it was also noted that insufficient buffers existed between the various processes and that bottlenecks would therefore quickly move to the other processes if not addressed simultaneously.

The mining team therefore considered the opportunities to create buffers and remove bottlenecks across all three mining disciplines (stripping, L\&H, and bedrock cleaning), identified the key focus areas, and then detailed plans around the implementation of the changes. Localized accretion is believed to be dependent on the stripping tons deposited on the beach and as such. stripping and accretion were considered jointly when defining the improvement plan. The improvement plan roll-out therefore began with stripping and accretion, followed by bedrock processes, and finally the $\mathrm{L} \& H$ operations. However, in practice, many of the improvement projects were implemented simultaneously.

\section{Planning and execution}

Before any of the improvement initiatives were introduced, it was critical that a 'solid' mine plan be developed; i.e. one with sufficient detail and realistic targets. Although the nature of the SCM mining operation requires flexibility that enables changes in the mining sequence, in reality this is time-consuming and disruptive to the process. The development of the plan therefore went through numerous reviews and revisions, considering various options and addressing possible risks. To mitigate risk budget planning included all key stakeholders, especially the high tension electrical team (HT) and the dewatering team. The timing of seawall moves, especially during winter months, was also changed to reduce budget plan risk profiles.

With a more 'rigid' plan in place, execution became critical. A weekly drive-through planning session was therefore initiated that included all relevant stakeholders, in order to align the whole team around the plan. All tasks and priorities were defined for each area with tracking of compliance to plan. This forum also improved communication across departments, enabling proactive engagement, operational input, and assistance when required. The drivethrough also became a key forum for ensuring the progression of improvement projects.

\section{Stripping and accretion}

When the ToC was applied within stripping, the key bottlenecks and improvement opportunities identified included:

> Long circuit distances that resulted in longer cycle times and reduced productivity

> Under-loaded trucks that resulted in reduced payloads and lower productivities

> Poor underfoot conditions that increased rolling resistance, reduced tramming speeds, and consequently lowered productivity rates

> Lack of redundancy of equipment that resulted in reduced fleet capacity when equipment was unavailable 


\section{Operational changes enable Namdeb's Southern Coastal Mining team to reduce risk}

> Poor water management in the cut that led to samebench loading and reduced productivity rates

> Dozing on the groynes that increased ADT queuing times and delayed tipping operations.

\section{Change in mining philosophy and layouts}

To reduce circuit distances, the mining philosophy and layouts had to be completely redesigned. Previously ADTs had exited the mining area on the eastern side of the cut, trammed along the crosswalls, and dumped the overburden material on 20-30 m wide groynes which pushed westwards into the sea. The most obvious solution was to build a ramp straight out of the mining cut, to the top of the seawall and then directly out onto the beach. This layout, however, caused significant challenges with water seepage into the mining cut through the seawall.

The solution was to divide the mining cut into a number of 200-300 m wide, north-south 'paddocks' and focus stripping on one paddock at time as illustrated in Figure 7. Stripping operations now commence at the paddock with the deepest bedrock elevation, Paddock 1, with a temporary ramp just within Paddock 2. Mining continues in Paddock 1 until the phreatic line is intersected and water starts to seep into the mining cut. The water is then channelled to the deepest side of the paddock where a sump and pump remove the water, pumping it back out to sea. Mining then continues in this paddock until bedrock elevations have been reached and permanent dewatering channels, a sump, and pumping infrastructure can be installed. Stripping teams then move to the second paddock where the previous temporary ramp is mined out and a new temporary ramp positioned just inside Paddock 3. By removing the first temporary ramp, water is then able to flow back into Paddock 1 where pumping infrastructure is now in place. This mining sequence is followed until the entire mining block has been completed.
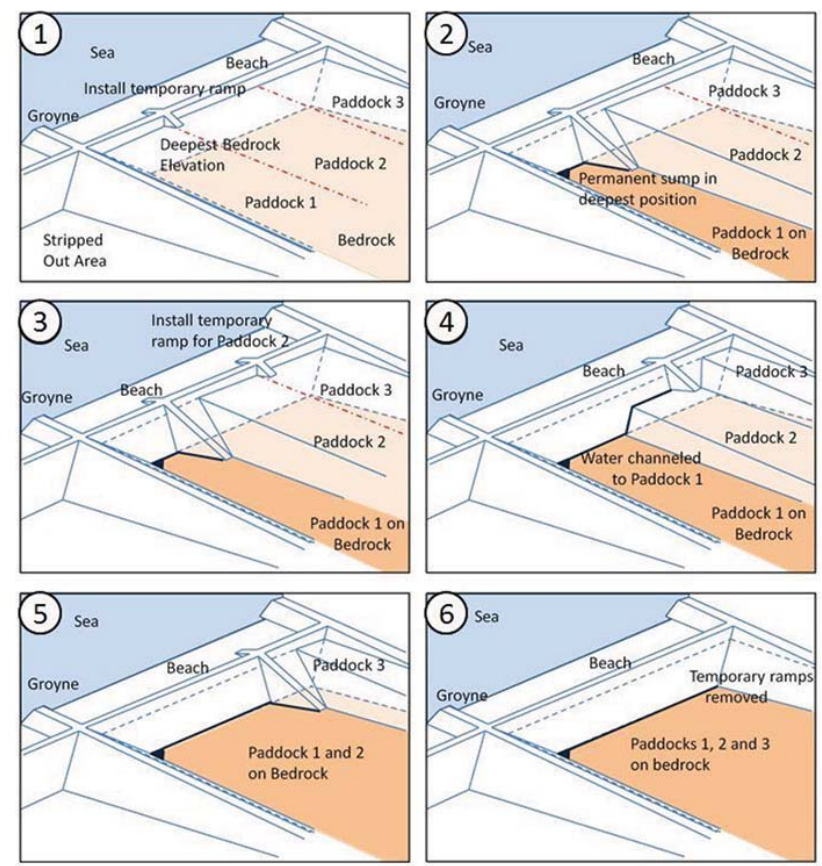

Figure 7-Graphical depiction of the new mining layouts and mining sequence at SCM, with temporary ramps on the west (seaward)
This philosophy has a number of advantages in addition to the obvious benefit of reduced cycle distances and cycle times. For example, with the initial paddock on bedrock and with pumping infrastructure in place, water management is far more effective, i.e. water flows away from the stripping cut. This allows for mining of bigger benches with increased bucket fill factors, and in addition, drier footwall conditions enabled more material to be loaded using a more productive, top loading configuration; i.e. excavator on the bench above the ADT. Both the bucket fill factor and loading set-up have added benefits by way of reducing loading times and improving productivity.

\section{Increase in payload}

The payload of the ADTs was noted to be well below loading capacity. Two options for improving payload were therefore considered; namely, installing greedy boards and/or tailgates. Greedy boards are fixed extensions to the side of the ADT bucket (Figure 8), while a tailgate is a mechanism installed at the back of a truck to allow more material to be loaded. Tailgates were considered more effective for loading wet material, but the higher cost and potential mechanical breakdowns of the tailgate mechanism was considered a major disadvantage. Greedy boards were successfully trialled on two trucks and then rolled out to the entire fleet. The greedy boards have increased the average payload capacity by 6 t or $20 \%$.

\section{Additional support equipment}

Underfoot conditions as a result of the 'soft', wet nature of the overburden beach sand were not conducive to creating hard, compact roads and as a result, the road conditions deteriorated quickly once stripping commenced. The poor road conditions resulted in high rolling resistance and reduced tramming speeds. To improve road conditions additional support equipment was purchased; two wheel dozers and an additional grader. The additional support equipment has subsequently become an integral part of the stripping process. Improved road conditions in the mining areas in conjunction with more compacted temporary ramps have resulted in higher average tramming speeds into and out of the mining cut.

\section{Excavator redundancy}

The ToC indicated that excavators remained a key bottleneck within the stripping process. As the prime mover, ADTs were reliant on the excavator availability to achieve production targets. With no redundancy within the system, whenever an

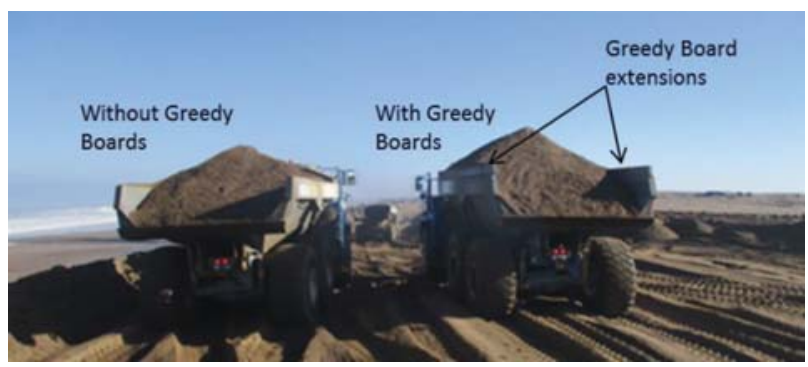

Figure 8-Photograph of two ADTs at SCM, one with greedy boards and one without 


\section{Operational changes enable Namdeb’s Southern Coastal Mining team to reduce risk}

excavator was taken out of production for scheduled maintenance, repairs, or auxiliary work such as digging sumps and channels, the stripping fleet was unable to achieve the required production targets. To mitigate against these scenarios, a fourth $80 \mathrm{t}$ excavator, referred to as a 'swing unit', was added to the fleet, increasing the utilization of the entire stripping fleet and improving production capacity.

\section{Beach nourishment}

While redesigning the stripping layouts and implementing the new mining philosophy, it was suggested that a new accretion methodology be considered for SCM. The new methodology, called beach nourishment, required a change from tipping on the groynes, or point deposition, to building elevated pads along the length of the beach. Although the SCM application of beach nourishment is unique in its aim to provide access to future offshore resources, this methodology is widely recognized and used around the world to protect onshore structures and infrastructure.

The beach nourishment methodology was initially implemented as a trial in one of the mining areas. Temporary ramps were extended from the top of the seawall onto the beach. Material was then tipped along the length of the beach, maintaining a floor elevation of 2-3 $\mathrm{m}$ AMSL. The beach nourishment pad created a bigger dumping area than was previously available when tipping on the crosswall groynes, with the added benefit of eliminating the delays experienced previously. The proximity of the dumping area was also generally closer to the temporary ramps, reducing tramming distances further.

The beach nourishment methodology showed improved localized advance rates of the beach westwards and exceeded predicted accretion lines in all active areas. An added significant benefit has been the protection that the beach nourishment pads have afforded the active mining areas. These pads have moved the erosive surf zone westwards, away from the seawall, and provided a barrier to dissipate wave energy. During a 1:20 year storm event which hit the west coast of Namibia on 7 June 2017, bringing with it $+8 \mathrm{~m}$ waves, many of the seawalls remained unaffected by the with the beach nourishment pads taking the full force of the storm and protecting the seawalls.

\section{Bedrock operation}

The ToC analysis at the bedrock operation identified the following bottlenecks:

> Low bedrock bulking rates, resulted in no bulking reserve for the bedrock cleaning process

- Areas with cracks and narrow gullies experiencing reduced cleaning rates

> Cementation reducing bulking rates.

\section{Backshift bulking}

Historically, bedrock business improvement projects have focused on bedrock cleaning and generally resulted in improved cleaning rates. However, the ToC analysis identified bedrock bulking as the bottleneck.

The area that has been bulked by the hydraulic equipment but not yet cleaned with the vacuum units is referred to as 'bulk reserve', and it was highlighted that not only was there limited buffer between the two processes but the advance rates of the bulking crew were lower than that of the cleaning crew. Analysis of equipment hours reinforced this observation. Reasons for slower bulking rates included deeper gullies, cemented material, and machine downtime.

The obvious solution was to increase the amount of machine hours of the bulking fleet. This could be achieved by either increasing the size of the bulking fleet or increasing the operating hours. Bedrock operations, both bulking and cleaning, were originally limited to day shift due to security concerns, despite the fact that the security risk generally only applies to bedrock cleaning. Therefore an additional afternoon bulking shift was implemented, increasing overall bulking advancement, creating bulking reserves, and enabling higher productivity of the bedrock cleaning crews.

\section{Removing slow cleaning areas}

With additional bulking capacity following the implementation of the backshift bulking team, it was now possible for the bulking teams to increase the amount of bedrock broken out, especially when narrow gullies and highly fractured areas were encountered. Traditionally the bulking teams would not break out these areas, cleaning out only the loose material and leaving the cleaning teams to clean all the cracks, fractures, and narrow gullies. This reduced cleaning rates but previously, as bulking remained the bottleneck, the cleaning teams would soon catch up. Additional bulking capacity enabled the bulking teams to also break out these areas, removing the cracks and gullies that previously slowed down the cleaning teams. Consequently, what had originally been a bottleneck for the cleaning teams is now removed by the bulking team with a knock-on overall productivity improvement of the bedrock teams.

\section{Increased hydraulic hammer capacity}

In the past, when cemented material was encountered the bulking and cleaning rates were significantly reduced. Breaking out cemented material was most effectively done using the hydraulic hammer, but often only one hydraulic hammer was available per bedrock site. The hydraulic hammer therefore became the bottleneck within the operation as soon as cementation was encountered. To address this problem, bedrock teams would move all hydraulic hammers to the site encountering the cementation, ultimately impacting on bedrock cleaning rates in other areas. Two changes were therefore adopted. Firstly, all excavators were fitted with hydraulic systems suitable for a hammer installation, and secondly, a larger hammer that could be fitted to the $80 \mathrm{t}$ 'swing unit' excavator was purchased. The fitting of the hydraulic hammer kits has enabled all the spare hammers to be fitted to excavators when cemented material is encountered, reducing the bottleneck. In extreme cases where cementation either covers vast areas or is very thick, the bigger hammer is fitted to the $80 \mathrm{t}$ swing unit excavator and the higher energy and greater breakout force increases the bulking rates. Although cementation remains a challenge to achieving bedrock production rates, improved tools have reduced the bottleneck.

\section{Load and haul}

ToC analysis at the plant feed identified the following bottlenecks where capacity was not optimally used:

> L\&H fleet capacity

> Mining delays impacting plant feed capacity. 


\section{Operational changes enable Namdeb's Southern Coastal Mining team to reduce risk}

\section{Redundancy}

The L\&H fleet originally comprised three FELs and seven trucks. In contrast to stripping, where the bottleneck was excavators, the L\&H bottleneck was the trucks. With high tramming distances and long cycle times the FELs had significantly more capacity than the trucks and any delays on the trucks therefore had a marked impact on productivity. A 'spare' truck was therefore added to the L\&H fleet as a redundant unit, used when one or more of the other trucks were unavailable.

\section{Tipping bin stockpile}

The fundamental bottleneck impacting plant feed capacity was a mismatch between the L\&H fleet capacity and the plant feed requirements, especially for mining areas far from the plant. The L\&H fleet, however, works continuous operations (CONTOPS) and therefore runs more hours than the plant, providing additional capacity while the plant is not running. The rehandling cost, however, had historically resulted in a reluctance to build stockpiles at the plant tipping bin and stockpiles were therefore minimal.

The ToC analysis of L\&H highlighted a lower hourly production rate of the $\mathrm{L} \& \mathrm{H}$ fleet than the required plant feed rates and, furthermore, minimizing stockpile levels left no buffer available to maintain the required feed capacity. This often translated into plant feed delays due to material unavailability while the plant was running. The L\&H teams therefore changed their focus to building stockpiles close to the plant tipping bin while the plant was not operational. They also positioned a FEL permanently at the tipping bin while the plant was running, enabling plant feed to be supplemented from the stockpiles and maximizing plant feed capacity. Allowing the $\mathrm{L} \& \mathrm{H}$ fleet to grow the tipping bin stockpile also ensured that $L \& H$ productivity was maintained at all times.

\section{Results}

\section{Stripping}

The stripping operation has consistently improved quarteron-quarter since Q2 2016 when the new mining philosophy and revised layout were introduced at SCM. In Q3 2017 a pipeline used during a previous dredge mining project was intersected in the stripping cut. The pipe was open to the sea and required that a concrete plug be pumped into it before it could be removed. Consequently, mining was relocated to another area, with longer tramming distances and lower efficiencies during this period. Once the pipeline was removed, the SCM stripping team reached a record high production rate in Q4 2017 of $35414 \mathrm{t} / \mathrm{d}$, up 49\% from the productivity achieved in Q1 2016 (Figure 9). Complementing the new mining philosophy, the introduction of beach nourishment, greedy boards, excavator redundancy, and support equipment has assisted in achieving continued productivity improvement.

\section{Bedrock}

An afternoon bulking shift, known as the back shift bulking team, was successfully trialled from July 2016, with a 55\% increase in hydraulic excavator hours and a $77 \%$ increase in vacuum hours. This project has translated into a $32 \%$ improvement, increasing monthly bedrock production from $30798 \mathrm{~m} 2 /$ month to $40612 \mathrm{~m} 2 /$ month (Figure 10). The additional bulking capacity has enabled bulking to create and sustain a bedrock buffer between the bulking and cleaning teams, as well as improve cleaning rates by removing cracks and gullies that are difficult to clean. Cemented material will remain a challenge for bedrock using the current cleaning techniques, but the introduction of additional hammer capacity has increased bulking rates in these conditions.

\section{Load and haul}

A buffer stockpile ahead of the plant feed has had a number of positive impacts on the operation. Consistent plant feed has increased the plant feed rates from $755 \mathrm{t} / \mathrm{h}$ at the beginning of 2015 to an average of $936 \mathrm{t} / \mathrm{h}$ in the last half of 2017 (Figure 11), an increase of $24 \%$. This has resulted from a $50 \%$ reduction of mining-related delays and a reduced impact of unscheduled delays. Although it is acknowledged that the philosophy of stockpiling material comes with an additional cost of rehandling, the benefits have shown that having a buffer ahead of the tipping bin has added significant value to the business. Work is currently underway to improve the current stockpile layouts and reduce loader cycle times.

\section{Conclusion}

Through the ToC process, the mining discipline was identified as the bottleneck at SCM. On further analysis of the mining processes, numerous local bottlenecks were identified that prevented optimum productivity. Buffers, which if managed

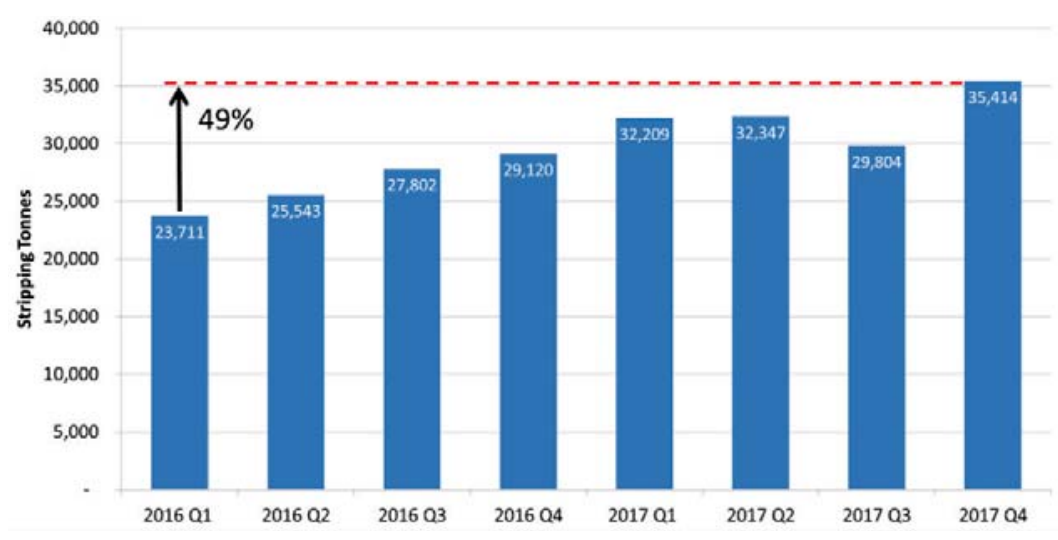

Figure 9-Average daily stripping production per quarter from 2016 to end of 2017 


\section{Operational changes enable Namdeb's Southern Coastal Mining team to reduce risk}

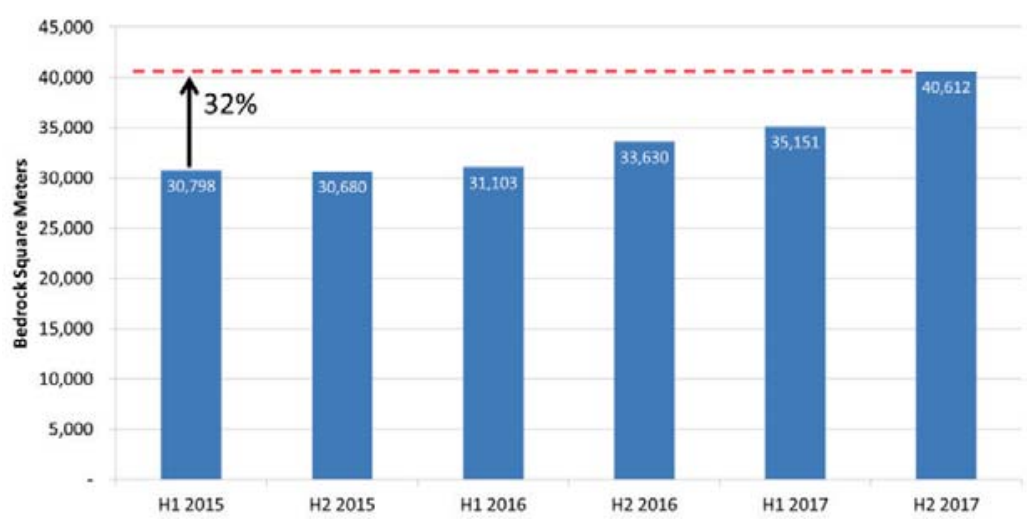

Figure 10-Average monthly square metre production per 6-month period from 2015 to end of 2017

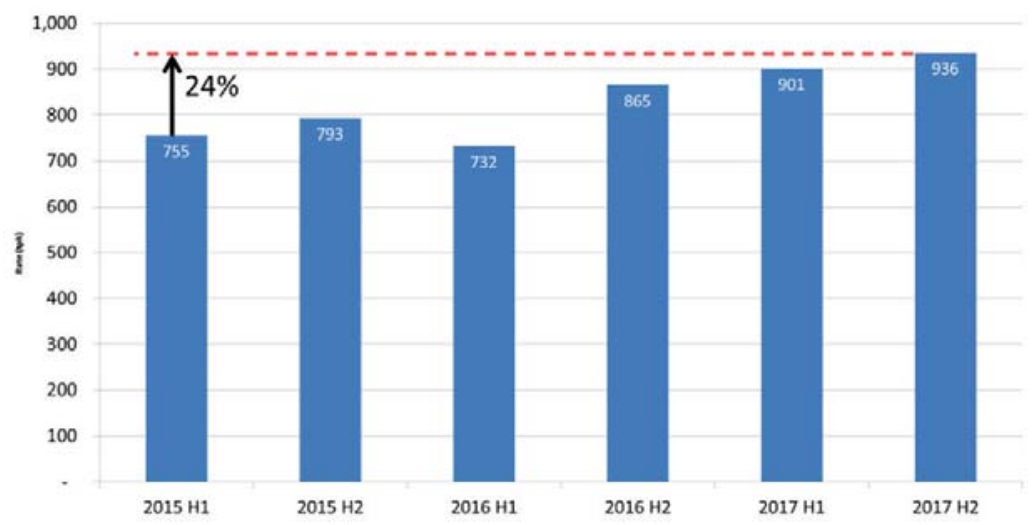

Figure 11-Average plant feed rates per 6-month period from 2015 to end of 2017

better could build capacity, were identified. Through a focused effort to address these bottlenecks and create buffers, solutions were developed and implemented that have greatly improved productivity, and in the case of beach nourishment reduced the risk of a storm breaching the seawall defence at Namdeb.

SCM will continue mining operations up and down the coastline and, more importantly, westward to exploit resources further into, and deeper under, the Atlantic Ocean. The associated challenges for the Namdeb team will continue to grow but we have embarked on a process of innovative and continuous improvement using the ToC method. The bottlenecks are expected to shift from one process to another as we find solutions that make previous processes more efficient and productive. The ultimate challenge is to apply the ToC continuously to define new bottlenecks and then focus on innovative solutions to remove these bottlenecks. Improved productivity and associated unit cost reduction will have significant benefit not only on the profitability of the mine in the short term, but also on the LoM potential of SCM going into the future.

\section{Acknowledgements}

The authors are grateful to Namdeb for the opportunity to compile this paper, with special acknowledgement to Paul Lombard, the SCM Mine Manager, for guidance and more importantly support. To the entire SCM Mining Team for openly embracing the changes and provided continual feedback and suggestions. To the SCM Management team, for the teamwork and support. Finally, Lynette Kirkpatrick for your support and hours of editing.

\section{References}

BADENHORST, S.H. 2003. The unique Namdeb trilogy - Our past, present and future mining applications in this unique deposit. Journal of the South African Institute of Mining and Metallurgy, vol. 103, November. pp. 539-349.

BLUCK, B.J., WARD, J.D., and DE WITT, M.C.J. 2005. Diamond mega-placers: southern Africa and the Kaapvaal craton in a global context. Mineral Deposits and Earth Evolution. McDonald, I., Boyce, A.J., Butler, I.B., Herrington, R.J., and Polya, D.A. (eds). Special Publication 248. Geological Society, London. pp. 213-245.

De DeсKER, R.H. 1988. The wave regime of the inner shelf south of the Orange River and its implications for sediment transport. South African Journal of Geology, vol. 91. pp. 358-371.

GoldratT, E.M. and Cox, J. 2004. The Goal - A Process of Ongoing Improvement. 3rd edn. North River Press, Great Barrington, MA.

JacoB, J., WARD, J.D., Bluck, B.J., Scholz, R.A., and Frimmel, H.E. 2006. Some observations on diamondiferous bedrock gully trapsites on Late Cainozoic, marine-cut platforms of the Sperrgebiet, Namibia. Ore Geology Reviews, vol. 28, no. 4. pp. 493-506.

ЈАсов, R.J. 2005. The erosional and Cainozoic depositional history of the lower Orange River, Southwestern Africa. PhD thesis, University of Glasgow, UK.

Rogers, J. 1977. Sedimentation on the continental margin off the Orange River and the Namib Desert. Bulletin no. 7. Geological Survey/University of Cape Town Marine Geoscience Unit, South Africa. 212 pp.

Rossouw, J. 1981. Wave conditions at Oranjemund: Summary of wave rider data. March 1976-April 1980. Report no. T/SEA 8106. CSIR, Stellenbosch, South Africa. pp. 1-4.

SchneIDER, G. 2008. The Treasure of the Diamond Coast - A Century of Diamond Mining in Namibia. 1st edn. Macmillian Education Namibia, Windhoek.

SPAGGIARI, R.I., BLUCK, B.J., and WARD, J.D. 2006. Characteristics of diamondiferous Plio-Pleistocene littoral deposits within the palaeo-Orange River mouth. Ore Geology Reviews, vol. 28. pp. 475-492.

Smith, G.G. and Soltau, C. 2003. Shoreline modelling insights from projects in Southern Africa. Proceedings of Coastal Sediments '03. World Scientific Publishing. https://doi.org/10.1142/5315 